\title{
PRÁTICAS, BENEFÍCIOS E OBSTÁCULOS NAS COMPRAS PÚBLICAS SUSTENTÁVEIS: UMA REVISÃO SISTEMÁTICA DE LITERATURA
}

\author{
Caroline Ornelas Paes \\ Mestre em Gestão Pública \\ Instituto Federal de Ciência e Tecnologia do Espírito Santo Vitória - ES - Brasil \\ linepaes@gmail.com \\ Izabel Eliani Zucoloto \\ Mestre em Gestão Pública \\ Instituto Federal de Ciência e Tecnologia do Espírito Santo Venda Nova do Imigrante - ES - Brasil \\ izabel.zucoloto@gmail.com \\ Mauro Rosa \\ Graduação em Engenharia Elétrica \\ Corpo de Bombeiros Militar do Espírito Santo Vitória - ES - Brasil \\ maurocbmes@gmail.com \\ Lourenço Costa \\ Doutor em Engenharia de Produção \\ Instituto Federal de Ciência e Tecnologia do Espírito Santo Vitória - ES - Brasil \\ lourenco.costa@ifes.edu.br
}

\section{RESUMO}

Este artigo visa fornecer uma revisão sistemática de literatura, abrangendo as publicações existentes sobre compras públicas sustentáveis, explorando as práticas utilizadas, os benefícios e os obstáculos, encontrados num contexto global. A metodologia consistiu num mapeamento sistemático das principais publicações sobre o tema, dividindo-as nas categorias de práticas, vantagens/benefícios e barreiras/obstáculos. A partir dos resultados obtidos pode-se observar que as práticas sustentáveis mais utilizadas nas contratações públicas são a adoção de critérios de performance ambiental, o uso de certificados e selos ambientais e de legislação específica para normalização das licitações. Os principais benefícios encontrados na aplicação das compras públicas sustentáveis referem-se à redução da emissão de gases do efeito estufa, estímulo a atitudes sustentáveis no setor privado, ao mercado de produtos sustentáveis e à inovação. Os estudos analisados indicam ainda que a prática de compras públicas sustentáveis precisa superar desafios significativos, incluindo a falta de informação sobre os produtos, problemas de ordem financeira, de conhecimento e conscientização ambiental.

Palavras-chave: Benefícios. Compra pública sustentável. Licitação sustentável. Obstáculos. Práticas.

\section{PRACTICES, BENEFITS AND OBSTACLES IN SUSTAINABLE PUBLIC PURCHASES: A SYSTEMATIC LITERATURE REVIEW}

\begin{abstract}
This paper provides a systematic literature review, covering existing publications on sustainable public procurement, exploring practices used, benefits and obstacles found in a global context. The methodology consisted of a systematic mapping of the main publications on the theme, dividing them into categories of practices, advantages / benefits and barriers / obstacles. From results of study, it can be observed that the sustainable practices most used in public contracting are the adoption of environmental performance criteria, the use of environmental certificates and seals, and the use of specific legislation to standardize bids. The main benefits of applying sustainable public procurement are the reduction of greenhouse gas emissions, the stimulation of sustainable attitudes in the private sector, stimulation of the market for sustainable products, and the innovation. The studies analyzed also indicate that the practice of sustainable public procurement needs to overcome significant challenges, including lack of product information, financial problems and lack of environmental knowledge and awareness.
\end{abstract}

Key words: Benefits. Obstacles. Practices. Sustainable bidding. Sustainable public procurement.

Data da submissão: $30 / 08 / 2018$

Data de aceite: $19 / 03 / 2019$ 


\section{INTRODUÇÃO}

O termo sustentabilidade está cada vez mais presente no ambiente organizacional. A preocupação com o desenvolvimento de forma sustentável nas organizações, apesar de incipiente, tem sido introduzida gradualmente no ramo dos negócios e na sociedade em geral.

O conceito instituído pela Comissão Mundial sobre Meio Ambiente e Desenvolvimento (Cmmad) da Organização das Nações Unidas (ONU), publicado no relatório Brundtland, ainda é o mais utilizado. Ele traz a preocupação da melhor gestão dos recursos naturais, pensando na geração atual e também nas gerações futuras.

A Cmmad define ainda os três pilares básicos (tripé da sustentabilidade) que devem ser considerados para o desenvolvimento sustentável, que são o econômico, o social e o ambiental (Cmmad, 1987). Não há que se falar em desenvolvimento sem levar em consideração o aspecto econômico, assim como é imprescindível o desenvolvimento da sociedade. Tendo em vista que os recursos naturais são limitados, existe também a necessidade de se preocupar com os impactos ambientais gerados para que ocorra o desenvolvimento.

Neste contexto, tanto o governo quanto o setor privado têm buscado a adoção de práticas sustentáveis, acompanhando a tendência mundial proposta pela Cmmad. E o Estado, como grande consumidor, sofrendo também a pressão de organismos internacionais, tem percebido a necessidade de realizar a aquisição de bens e serviços de modo a promover também o desenvolvimento sustentável.

No âmbito das compras públicas, a preocupação com o desenvolvimento sustentável teve início com o conceito de licitação verde, em que as entidades governamentais buscavam obter serviços e produtos que atendessem aos requisitos ambientais. Entretanto, nos últimos anos, as contratações públicas verdes se estenderam para as compras públicas sustentáveis, que envolvem a incorporação de considerações ambientais e sociais, além das econômicas, na aquisição de bens e serviços (Uttam e Roos, 2015).

As compras públicas sustentáveis atuam como uma estratégica na organização pública, constituindo um grande instrumento na busca pela manutenção do bem-estar social e preservação dos recursos naturais, com benefícios para toda a sociedade. Segundo o Guia de Compras Públicas Sustentáveis do Ministério do Meio Ambiente, "A Licitação Sustentável permite o atendimento das necessidades específicas dos consumidores finais por meio da compra do produto que oferece o maior número de benefícios para o ambiente e a sociedade" (Biderman et al., 2008, p. 25).

De acordo com Pacheco-Blanco e Bastante-Ceca (2016), os governos devem mostrar comprometimento com políticas que incentivem as compras públicas sustentáveis, criar banco de dados de produtos sustentáveis e disseminar iniciativas e produtos com o intuito de promover o uso de produtos e serviços considerados verdes e, assim, promover o desenvolvimento sustentável. No entanto, embora existam normas e legislações a respeito das compras sustentáveis no setor público, o tema ainda é tratado com certa discrição pelos gestores públicos de alguns países, na maioria dos casos, devido a questões regulatórias e de falta de conhecimento. Ainda assim, a implementação das compras sustentáveis tem sido ampliada para novos setores da administração pública nos últimos anos, como é o caso do segmento da saúde (Ahsan e Rahman, 2017; Chiarini et al., 2017) e da produção e fornecimento de refeições (Neto e Caldas, 2018).

Como as contratações sustentáveis estão desempenhando um papel cada vez mais importante no estímulo à demanda por produtos e serviços ambientalmente corretos, existe uma necessidade emergente de analisar como está ocorrendo a inclusão de critérios socioambientais nas licitações públicas e quais os resultados obtidos com essa iniciativa.

Nesse sentido, este estudo tem por objetivo identificar na literatura atual as práticas sustentáveis atualmente utilizadas, benefícios e obstáculos referentes às compras públicas sustentáveis, num contexto global.

A partir desta revisão de literatura, espera-se contribuir para a disseminação da prática da compra pública sustentável e suscitar nas organizações públicas o interesse em potencializar suas ações em busca do desenvolvimento sustentável.

\section{FUNDAMENTAÇÃO TEÓRICA}

Com a evolução da era industrial e a constatação de que os recursos naturais são finitos, verifica-se uma crescente necessidade em se adotar práticas sustentáveis nas organizações. Desenvolver-se sustentavelmente significa crescer economicamente, realizando práticas que contribuam com a vida das pessoas e com o meio ambiente.

Revista de Gestão Social e Ambiental - RGSA, São Paulo, v. 13, n. 2, p. 21-39, maio/ago. 2019. 
Para Urban (2015), existem três elementos centrais no desenvolvimento sustentável: (i) a formulação de políticas econômicas deve refletir um compromisso com considerações ambientais; (ii) deve haver um compromisso com a equidade social, que inclui a criação de riqueza e a conservação de recursos, bem como a distribuição justa de ambos; (ii) o desenvolvimento deve considerar a melhoria qualitativa além do crescimento econômico.

Neste sentido, o desenvolvimento sustentável deve ter um caráter holístico e ser um compromisso do governo, da sociedade e daqueles que utilizam os recursos naturais para produção, de modo que os frutos oriundos desse desenvolvimento sejam distribuídos de forma justa. Portanto, promover o crescimento econômico não deve ser a única preocupação de governos e organizações, mas desenvolver-se de maneira sustentável significa principalmente promover a melhoria na qualidade de vida das pessoas.

$\mathrm{Na}$ esfera governamental, o setor público possui um grande poder de compra que pode contribuir substancialmente para o desenvolvimento sustentável (Walker e Brammer, 2012), porém poucos artigos tratam da cadeia produtiva sustentável nesse ramo da economia (Mitra e Webster, 2008). Considerando as pressões ambientais diretas e indiretas, Defra (2006) estimou que mais de $50 \%$ do impacto ambiental do setor público provém das cadeias de fornecimento de produtos. Seguindo as premissas internacionais para o desenvolvimento sustentável, uma prática adotada nas organizações públicas vem sendo, ainda que incipiente, a realização de contratações sustentáveis.

\subsection{Compras sustentáveis nos setores público e privado}

Compra sustentável é um campo de pesquisa atual e em crescimento, mas ainda com muitas lacunas a serem preenchidas (Walker et al., 2012). As aquisições proporcionam uma grande oportunidade de agregar aspectos ambientais nos processos de uma organização (Appolloni et al., 2014), e as compras são potencialmente consideradas um dos agentes de mudança mais importantes dentre as atividades corporativas de uma organização (Preuss, 2001).

De acordo com a Sustainable Procurement Task Force (2006), a compra sustentável é um processo onde as organizações fazem aquisições satisfazendo suas necessidades de forma a gerar benefícios não apenas para a própria organização, mas também para a sociedade e para economia, sem degradar o meio ambiente. Walker e Brammer (2012) definem compra sustentável como a busca pelos objetivos do desenvolvimento sustentável por meio de aquisições, levando em consideração os aspectos econômico, social e ambiental. Ao adotarem práticas sustentáveis, as organizações fomentam a produção sustentável e promovem o desenvolvimento sustentável, contribuindo com o meio ambiente, o tecido social e a economia.

As contratações de bens e serviços são realizadas de forma diferenciada no setor público e no setor privado. De acordo com Ambe e Badenhorst-Weiss (2012), o setor privado é orientado pela maximização do lucro, enquanto o setor público foca na entrega e num serviço de qualidade. A realização de contratações sustentáveis nas organizações públicas e privadas contribui para o fortalecimento da produção sustentável, especialmente em nível local. Esse tipo de aquisição pode aumentar diretamente a demanda por indústrias verdes em determinadas regiões (Rebane e Reihan, 2016).

Nos últimos anos, tanto as organizações públicas quanto as privadas têm buscado realizar suas compras buscando a aquisição de bens e serviços sustentáveis. Os organismos internacionais foram determinantes para que isso acontecesse, em especial a Cmmad, das nações unidas.

Todavia, as compras sustentáveis, tanto na esfera pública quanto na privada, ainda devem percorrer um longo caminho para se consolidarem, seja por falta de produtos com essa denominação, seja pela ausência de critérios de sustentabilidade na realização da compra. Além disso, o custo dos produtos sustentáveis, o desconhecimento ou desinteresse pelo assunto por parte das organizações também podem limitar as aquisições sustentáveis. McMurray et al. (2014) citam também a falta de orientação e conscientização para compras sustentáveis e a escassez de recursos como barreiras ao engajamento nas contratações sustentáveis.

Outro desafio para as contratações sustentáveis é a mensuração do grau de sustentabilidade de um bem ou serviço. Para Lehtinen (2012), é necessário que se tenha uma definição clara e não ambígua dos critérios de sustentabilidade utilizados no processo de compra, tanto para empresas locais quanto para fornecedores públicos, quando a sustentabilidade é destacada como um critério de aquisição ou competitivo.

No setor privado, quando não estão atendendo a imposições legais, as aquisições sustentáveis são realizadas de forma mais livre, de acordo com os procedimentos e princípios determinados pela organização e pelo mercado.

Revista de Gestão Social e Ambiental - RGSA, São Paulo, v. 13, n. 2, p. 21-39, maio/ago. 2019. 
Appolloni et al. (2014) realizaram uma revisão do estado da arte das compras sustentáveis no setor privado e identificaram que as principais motivações para esse tipo de aquisição são: benefícios financeiros; comprometimento pessoal dos gestores; legislação; pressão dos consumidores; pressão dos concorrentes; e pressão da sociedade como um todo. Esses autores também identificaram que algumas das principais motivações são, por vezes, identificadas como barreiras, como o caso da legislação, que é vista por algumas empresas como uma inibidora da inovação, além da questão econômica, que se apresenta como a principal preocupação das organizações.

$\mathrm{Na}$ administração pública em geral, essas contratações e aquisições são realizadas por meio de procedimentos regulados por legislação. No Brasil, existem diversas legislações para este fim, em especial a Lei $\mathrm{n}^{\circ} 8.666 / 1993$, de modo que as aquisições públicas seguem princípios de justiça, equidade, transparência, competitividade e custo-benefício. Como o setor público está focado no bem-estar social, isso o torna mais propenso a buscar a sustentabilidade (Walker e Brammer, 2012).

O governo é um dos principais disseminadores da sustentabilidade e deve exercer pressão coercitiva sobre as organizações, por meio das legislações, para passarem a adotar práticas de compras sustentáveis (Ahsan e Rahman, 2017). Quando existem políticas ou legislações relativas a compras sustentáveis, essas são vastamente implementadas, porém quando as diretivas são voluntárias outras prioridades se tornam dominantes (Brammer e Walker, 2011). Para que isso ocorra, é fundamental que os órgãos governamentais dêem o exemplo, por meio da incorporação de critérios de sustentabilidade nos seus processos de compras.

Neste cenário, é preciso atentar também para a obediência a normas que não violem os princípios que, normalmente, permeiam as aquisições públicas. Isso significa que a contratação sustentável requer empenho e conhecimento, para que seja usada como uma estratégia competitiva da organização, caso contrário, pode acontecer o favoritismo, que é associado a ineficiência (Brammer e Walker, 2011). Entretanto, Lundberg et al. (2016) destacam que a implementação de compras públicas poderá fazer com que o fornecedor evite o custo de se ajustar aos critérios ambientais e não participe do processo de aquisição.

Apesar de alguns aspectos diferenciais existentes entre compras públicas e privadas, é possível implementar políticas e práticas de contratos públicos alinhados com objetivos privados (Preuss, 2011). Na busca crescente de melhoria nas compras públicas, um alinhamento de políticas que visem o interesse mútuo é de fundamental importância. Estratégias econômicas e ambientais fundamentais da União Europeia e consagradas na Europa 2020, por exemplo, procuram deslocar a enorme demanda do setor público para compras sustentáveis, precisamente para estimular as empresas a inovar e alcançar padrões cada vez mais elevados de desempenho ambiental para seus produtos (Kunzlik, 2013). Isso torna os produtos melhorados disponíveis para a economia mais ampla, aumentando a eficiência dos recursos, melhorando a competitividade dos custos da indústria e mantendo a sua vantagem internacional nas tecnologias ambientais. Este estímulo pode influenciar os compradores públicos a exigir normas ambientais mais elevadas.

Entretanto, para alcançar um nível mais elevado de sustentabilidade, os governos precisam adaptar continuamente suas atividades de compras às inovações do mercado (Grandia, Steijn, Kuipers, 2015).

\subsection{Compras públicas sustentáveis: reflexos de sua implantação}

As aquisições de bens e serviços no setor público respondem por cerca de $18 \%$ a $30 \%$ do Produto Interno Bruto (PIB) nos países membros da Organização para a Cooperação e Desenvolvimento Econômico (Ocde) (Iclei, 2015). Isso torna o uso de critérios de sustentabilidade nos contratos públicos uma maneira muito eficaz de estimular a produção de produtos mais sustentáveis. De acordo com Alencastro et al. (2014, p. 214), as compras públicas sustentáveis constituem "[...]um processo no qual os órgãos governamentais procuram inserir critérios de sustentabilidade socioambiental nas práticas voltadas para a aquisição de bens e contratação de serviços".

De um modo geral, a compra pública sustentável é uma estratégia vantajosa para o Estado, que é um dos maiores consumidores de produtos e serviços. E, ao promover o desenvolvimento sustentável, o Estado incentiva a prática da produção sustentável, contribuindo com o meio ambiente, o social e a economia.

Testa et al. (2016) afirmam que as compras públicas sustentáveis têm o poder de estimular as empresas a investirem em soluções inovadoras, seja a nível tecnológico ou organizacional, podendo ser utilizada como um instrumento político ambiental capaz de trazer benefícios ambientais e melhoria competitiva de uma organização.

Ao implementarem práticas de contratações sustentáveis, as organizações públicas alcançam diversas vantagens e benefícios, mas também se deparam com barreiras e obstáculos, o que torna necessário adotar a sustentabilidade como uma estratégia da organização. Portanto, se os gerentes seniores apoiarem a 
sustentabilidade e incorporarem as contratações públicas no planejamento, nas estratégias e na definição de metas, a equipe de compras automaticamente as implementam (Brammer e Walker, 2011). Dessa forma, torna-se primordial o engajamento de toda a instituição, em todos os níveis, estratégico, tático e operacional, para que as atitudes sustentáveis de aquisição pública sejam implantadas.

Dentre outros benefícios advindos das contratações sustentáveis, Adjei (2010) destaca: (i) redução das emissões nocivas e da geração de resíduos; (ii) melhoria na qualidade do ar e da água; (iii) melhoria nas condições de trabalho; (iv) melhoria na condição de grupos desfavorecidos; (v) melhoria na qualidade de vida da sociedade; (vi) melhoria no comportamento ético de fornecedores/contratados. Embora existam diversas vantagens na adoção da sustentabilidade nos processos de compras, seus impactos normalmente são de longo prazo, o que se contrapõe ao retorno imediato, que comumente é buscado pelas organizações. Ainda como barreiras, estão a falta de informação sobre o real impacto ambiental dos produtos, a dificuldade de encontrar fornecedores e de definir diretrizes para as compras (Testa et al., 2016).

Outro fator que deve ser considerado é a dificuldade que algumas organizações públicas enfrentam para a implementação das compras sustentáveis. As preocupações financeiras ainda continuam a ser a maior barreira para as contratações sustentáveis, com os compradores do setor público resistindo a pagar mais caro para comprar de forma sustentável (Brammer e Walker, 2011). Uma das razões para isso é que os recursos governamentais repassados para cada órgão são limitados. Além disso, as legislações obrigam contratações pautadas pela proposta mais vantajosa, que, na maioria das vezes, se refere simplesmente à de menor custo. Para Palacios e Ángel (2014), isto implica na necessidade de uma mudança de paradigma em matéria de contratos públicos, onde os princípios norteadores da contratação não visem somente assegurar uma concorrência com igualdade de condições para o fornecedor e o menor valor de aquisição.

Neste aspecto, quando se têm legislações voltadas para aquisições sustentáveis, o critério preço dá espaço também para a sustentabilidade. E confirma a necessidade de se ter o desenvolvimento sustentável instituído desde os níveis estratégicos das organizações e do governo. Brammer e Walker (2011) destacam que, se a política governamental e a legislação apoiam a contratação sustentável, as organizações do setor público são mais propensas a implementá-las. Neste sentido, os autores destacam que os formuladores de políticas devem estar atentos à ênfase que atribuem aos vários aspectos da contratação sustentável, pois existem diferentes interpretações entre países, e não há um modo correto de abordá-las.

Brammer e Walker (2011) identificaram quatro fatores que influenciam diretamente na implantação de práticas de compras públicas sustentáveis: (i) percepção de custo e benefícios; (ii) disponibilidade de produtos e serviços sustentáveis; (iii) pressão organizacional; e (iv) familiaridade com as políticas e regulamentações. Powell et al. (2006) argumentam que o conhecimento das regulamentações estimula as compras públicas sustentáveis, enquanto Testa et al. (2016) defendem que o uso de práticas sustentáveis nas compras públicas é determinado principalmente por ações e crenças dos indivíduos nas organizações, e não pela estrutura organizacional em si. Assim, a disseminação do tema compras públicas sustentáveis e o compartilhamento de informações são fatores cruciais para quebrar barreiras e ampliar as práticas sustentáveis.

\section{MÉTODO DE PESQUISA}

De acordo com Kitchenham (2007, p. 3), uma revisão sistemática de literatura é “[...]um meio de identificar, avaliar e interpretar toda a pesquisa disponível relevante para uma questão de pesquisa em particular, ou área temática, ou fenômeno de interesse".

O objetivo deste estudo é obter uma visão geral sobre a área de compras públicas sustentáveis, por meio de uma revisão sistemática de literatura, abrangendo as principais literaturas publicadas sobre o tema.

A estratégia realizada nesta revisão sistemática tomou como base as diretrizes propostas por Kitchenham (2007). Para obtenção dos dados da pesquisa, iniciou-se com a definição e elaboração do protocolo de revisão, que especificam os métodos a serem usados para realizar a revisão sistemática. A Figura 1 esquematiza, de forma sucinta, este protocolo.

Revista de Gestão Social e Ambiental - RGSA, São Paulo, v. 13, n. 2, p. 21-39, maio/ago. 2019. 


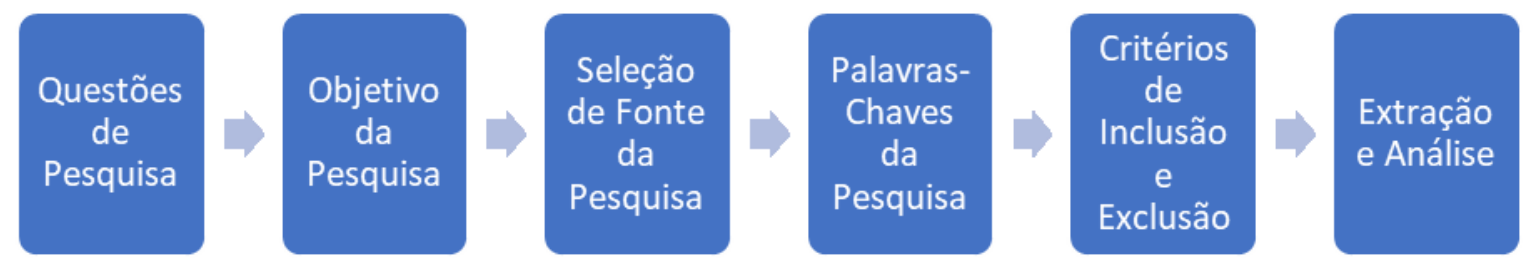

Figura 1 - Protocolo da revisão sistemática de literatura Fonte: Elaborado pelos autores

As questões de pesquisa (Tabela 1) elaboradas para mapear e estruturar este estudo concentraram-se em identificar e categorizar aspectos de sustentabilidade relacionados às compras públicas.

Tabela 1 - Questões de pesquisa do estudo

\begin{tabular}{|c|c|c|}
\hline Número & Questão de Pesquisa & Objetivo \\
\hline QP1 & $\begin{array}{l}\text { Quais são os obstáculos e/ou } \\
\text { barreiras encontrados nas compras } \\
\text { públicas sustentáveis? }\end{array}$ & $\begin{array}{l}\text { A resposta desta questão possibilita encontrar na literatura } \\
\text { pesquisada, quais as principais barreiras e ou obstáculos } \\
\text { encontrados ao se realizar uma compra pública que } \\
\text { considera os aspectos da sustentabilidade. }\end{array}$ \\
\hline QP2 & $\begin{array}{l}\text { Quais as práticas que estão sendo } \\
\text { utilizadas nas compras públicas } \\
\text { sustentáveis? }\end{array}$ & $\begin{array}{l}\text { A resposta para esta questão propicia encontrar na literatura } \\
\text { pesquisada, as práticas sustentáveis realizadas no processo } \\
\text { de compras públicas. }\end{array}$ \\
\hline QP3 & $\begin{array}{l}\text { Quais os benefícios e as vantagens } \\
\text { obtidos ao se realizar as compras } \\
\text { públicas sustentáveis? }\end{array}$ & $\begin{array}{l}\text { A partir desta questão, busca-se obter na literatura } \\
\text { pesquisada as vantagens e os benefícios oriundos das } \\
\text { compras públicas sustentáveis. }\end{array}$ \\
\hline
\end{tabular}

Fonte: Elaborado pelos autores.

\subsection{Processos para desenvolvimento da pesquisa}

Após realizar o planejamento da pesquisa, inicia-se a fase de realização da revisão sistemática de literatura. O processo de pesquisa e análise da literatura deve ser o mais fiel possível ao protocolo esquematizado e realizado de forma transparente, de modo a mapear o estudo desenvolvido e elevar o rigor da revisão de literatura. As seções que se seguem descrevem as etapas conduzidas de busca, seleção e análise da literatura no estudo de mapeamento.

\subsubsection{Seleção das fontes de dados e estratégias de busca}

As fontes de dados utilizadas devem ser diversas, a fim de reduzir a possibilidade de polarização da pesquisa. As bases de dados escolhidas foram as bibliotecas digitais contidas no Portal de Periódicos Capes (Coordenação de Aperfeiçoamento de Pessoal de Nível Superior). Este portal reúne, em um único espaço virtual, as melhores publicações científicas do mundo. As principais bases de dados pesquisadas incluem Elsevier, Springer Link, Science Direct, Emerald Insight, Google Scholar, Ieee Explore, ISI Web of Science, Jstor, Scopus e Wiley Online Library.

A estratégia de busca foi definida de maneira a encontrar na literatura as fontes de dados mais recentes e abrangentes. O idioma definido para a busca no portal foi o inglês, por abranger um número maior e mais diversificado de trabalhos. A busca se concentrou nos títulos, nos resumos e nas palavras-chaves de artigos científicos. Além disso, nas buscas realizadas, foram considerados os estudos publicados a partir de 2012, ou seja, as publicações dos últimos cinco anos.

A sequência de buscas nas bases de dados iniciou-se por meio da combinação de diversos termos relacionados aos objetivos da pesquisa, gerando a seguinte string de busca: ("sustainable public" AND (criteria OR practice OR strateg* OR obstacle OR barrier OR challeng* OR opportunit* OR benefit)), a qual retornou um total de 784 artigos. Todavia, por ser uma busca muito abrangente, observou-se nos resultados que havia muito conteúdo não aproveitável. Considerando que a string de pesquisa poderia ser melhorada, ela foi descartada e buscou-se gerar novas combinações de palavras. 
A Tabela 2 apresenta um resumo das buscas empreendidas e os resultados encontrados.

Tabela 2 - Buscas realizadas nas bases de dados

\begin{tabular}{|c|c|c|}
\hline Busca & String de busca & $\begin{array}{l}\text { Quantidade } \\
\text { de artigos }\end{array}$ \\
\hline 1 & $\begin{array}{l}\text { ("sustainable public" AND (procurement OR purchasing) AND (criteria OR } \\
\text { practice OR strateg* OR obstacle OR barrier OR challeng* OR opportunit* OR } \\
\text { benefit)) }\end{array}$ & 249 \\
\hline 2 & $\begin{array}{l}\text { ("sustainable procurement" AND public AND (criteria OR practice OR strateg* } \\
\text { OR obstacle OR barrier OR challeng* OR opportunit* OR benefit)) }\end{array}$ & 377 \\
\hline 3 & $\begin{array}{l}\text { ("green procurement" AND public AND (criteria OR practice OR strateg* OR } \\
\text { obstacle OR barrier OR challeng* OR opportunit* OR benefit)) }\end{array}$ & 402 \\
\hline 4 & $\begin{array}{l}\text { ("green purchasing" AND public AND (criteria OR practice OR strateg* OR } \\
\text { obstacle OR barrier OR challeng* OR opportunit* OR benefit)) }\end{array}$ & 584 \\
\hline 5 & $\begin{array}{l}\text { ("sustainable purchasing" AND public AND (criteria OR practice OR strateg* } \\
\text { OR obstacle OR barrier OR challeng* OR opportunit* OR benefit)) }\end{array}$ & 148 \\
\hline \multirow[t]{2}{*}{6} & $\begin{array}{l}\text { ("green public" AND (procurement OR purchasing) AND (criteria OR practice } \\
\text { OR strateg* OR obstacle OR barrier OR challeng* OR opportunit* OR benefit)) }\end{array}$ & 354 \\
\hline & TOTAL & 2114 \\
\hline
\end{tabular}

Fonte: Elaborado pelos autores

A etapa seguinte consistiu em analisar o título, resumo e palavras-chave dos artigos préselecionados, buscando uma correlação com o tema da pesquisa, a fim de que artigos irrelevantes fossem descartados.

\subsubsection{Critérios de inclusão e exclusão}

A pesquisa abrangeu somente artigos científicos, excluindo-se livros, escritos jornalísticos, artigos de opinião, dissertações, relatórios, livros e outros. Isso se justifica pelo fato de o estudo ter o objetivo de analisar as atividades de pesquisa no campo de compras públicas sustentáveis, onde a qualidade e o conteúdo dos documentos e a integridade da pesquisa devem ser assegurados.

$\mathrm{O}$ conjunto de estudos encontrados na literatura abrangeu diversos artigos sobre compras sustentáveis ou compras públicas, porém somente aqueles relacionados às compras públicas sustentáveis foram mantidos. A Tabela 3 resume o procedimento adotado para exclusão dos artigos analisados.

\section{Tabela 3 - Análise e exclusão de estudos}

\begin{tabular}{lcc}
\hline \multicolumn{1}{c}{ Análise } & Quantidade excluída & Quantidade final \\
\hline $\begin{array}{l}\text { Busca por meio de todas as combinações de strings finais. } \\
\text { Leitura do título, resumo e palavras-chaves. Exclusão dos artigos } \\
\text { que não pertenciam ao tema da pesquisa. }\end{array}$ & - & 2114 \\
$\begin{array}{l}\text { Exclusão por duplicidade } \\
\text { Leitura minuciosa dos artigos buscando resposta às questões de } \\
\text { pesquisa }\end{array}$ & 1896 & 218 \\
\hline
\end{tabular}

Fonte: Elaborado pelos autores

Após a fase de exclusão dos artigos, iniciou-se a etapa de extração e análise, conforme definido no protocolo de pesquisa.

\subsubsection{Extração e análise}

Nesta fase, os artigos selecionados foram lidos integralmente para a extração dos dados referentes às questões de pesquisa. Cada conteúdo extraído foi classificado de acordo com uma categoria que representa uma questão de pesquisa: (i) práticas; (ii) barreiras e/ou obstáculos; e (iii) benefícios e/ou vantagens. 
Os artigos foram enumerados e identificados com um código, a fim de manter a rastreabilidade dos resultados. No decorrer da análise não foi necessário modificar ou incluir novas categorias, além daquelas definidas inicialmente, porém alguns artigos necessitaram de uma releitura para definição mais precisa de sua classificação. Os artigos em geral possuíam elementos classificados em mais de uma categoria, ou seja, abordavam práticas, benefícios/vantagens e barreiras/obstáculos ao mesmo tempo.

A lista dos 52 artigos analisados e de onde foram extraídos os dados da pesquisa encontra-se no Apêndice A.

\section{RESULTADOS E DISCUSSÃO}

Nesta seção, os resultados são apresentados de acordo com as questões de pesquisa. Alguns artigos analisados apresentaram diversas evidências de uma ou mais categorias. As evidências da utilização de práticas sustentáveis nas compras públicas correspondem a duas vezes mais que as de barreiras/obstáculos ou vantagens/benefícios. Foram identificados 45 artigos contendo práticas sustentáveis, 23 artigos com barreiras e 23 artigos com vantagens (Figura 2). Esta constatação pode estar relacionada à necessidade de se estudar 0 modo como as organizações públicas estão implementando no seu dia a dia as compras sustentáveis, na direção do aprimoramento desse processo.

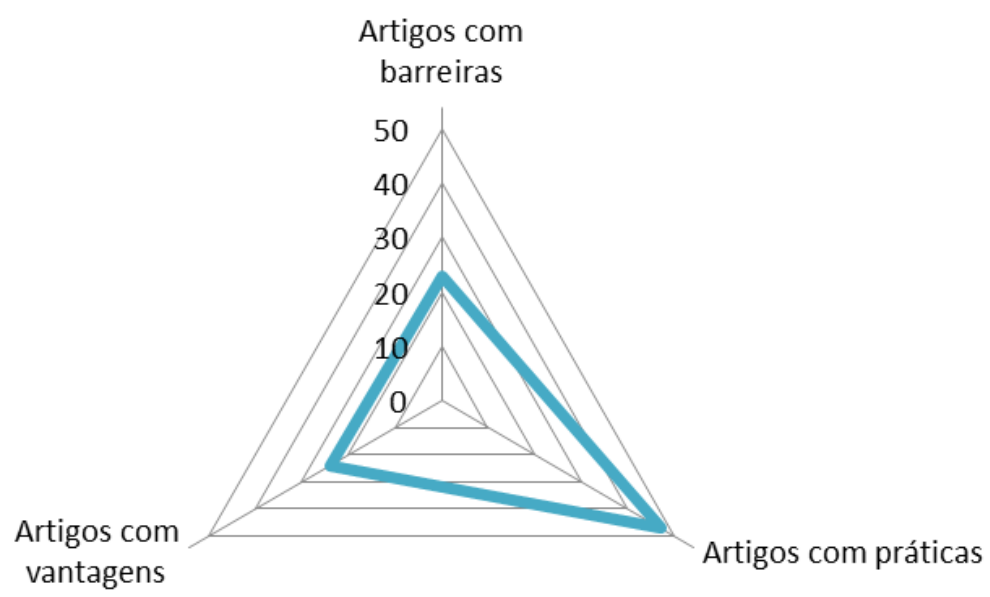

Figura 2-Quantidade de artigos por categoria

Fonte: Elaborado pelos autores

\subsection{Práticas sustentáveis nas compras públicas}

Nos artigos que apresentaram alguma prática sustentável adotada no processo de compras públicas, foram identificados 33 tipos distintos de práticas, listados na Tabela 4.

Tabela 4 - Práticas nas compras públicas sustentáveis

\begin{tabular}{lc}
\multicolumn{1}{c}{ Práticas } & $\begin{array}{c}\text { Quantidade de } \\
\text { artigos }\end{array}$ \\
\hline [P01] Utilização de critérios de performance ambiental na avaliação dos produtos & 19 \\
[P02] Exigência de Certificados Ambientais (Ecolabel) & 17 \\
[P03] Exigência de atendimento a legislações específicas & 13 \\
[P04] Aquisição de produtos reutilizáveis/reutilizados ou recicláveis/reciclados & 13 \\
[P05] Logística com uso de menos energia ou combustível alternativo & 11 \\
[P06] Aquisição de produtos locais & 9 \\
[P07] Critérios relativos a emissão de gases do efeito estufa ou outros poluentes & 8 \\
[P08] Aquisição de produtos com selos de eficiência energética ou pegada ecológica do & 8 \\
produto & 6 \\
[P09] Critérios de geração de resíduos sólidos & 6
\end{tabular}

Revista de Gestão Social e Ambiental - RGSA, São Paulo, v. 13, n. 2, p. 21-39, maio/ago. 2019. 
[P11] Custo relacionado ao ciclo de vida do produto 6

[P12] Destinação correta dos resíduos $\quad 5$

[P13] Exigência de padrões de empregabilidade $\quad 5$

[P14] Minimização/redução de embalagens $\quad 5$

[P15] Exigência de produtos biodegradáveis $\quad 5$

[P16] Contratação de empresas menos competitivas 4

[P17] Práticas de colheita / extração de matéria-prima / criação animal 4

[P18] Aquisição de produtos Fairtrade 3

[P19] Aquisição de produtos orgânicos 3

[P20] Utilização de políticas governamentais 3

[P21] Restrição de produtos que contenham material contaminante/tóxico 3

[P22] Aquisição de produtos com critérios de acessibilidade $\quad 2$

[P23] Aquisição de produtos com embalagens retornáveis 2

[P24] Aquisição de produtos de técnicas ou tecnologias novas 2

[P25] Aquisição de produtos sazonais $\quad 2$

[P26] Critérios de geração de poluentes lançados na água $\quad 2$

[P27] Diálogo com fornecedores e outros stakeholders 2

[P28] Exigência de conhecimento técnico para contratação de serviços 2

[P29] Incentivo a empresas locais para produção de produtos sustentáveis 2

[P30] Exigência de manuais e materiais de suporte disponíveis 2

[P31] Distribuição de documentos e mensagens de maneira eletrônica $\quad 1$

[P32] Minimização/redução de resíduos 1

[P33] Profissionalização da mão de obra 1

Fonte: Elaborado pelos autores

As seis práticas sustentáveis mais citadas nos artigos analisados somaram $46 \%$ do total desta categoria (Figura 3).

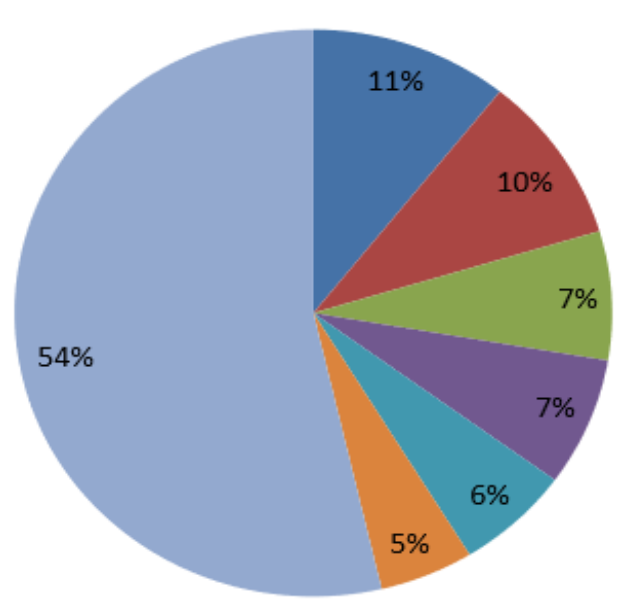

- Utilização de critérios de performance ambiental na avaliação dos produtos

n Exigência de Certificados Ambientais (Ecolabel)

[ Exigência de atendimento a legislaç๊es específicas

n Aquisição de produtos reutilizaveis/reutilizados ou recicláveis/reciclados

n Logística com uso de menos energia ou combustível alternativo

n Aquisição de produtos locais

m Outros

Figura 3 - Práticas sustentáveis mais citadas Fonte: Elaborado pelos autores

Ao abordar critérios de performance ambiental, os artigos descrevem a necessidade de se exigir dos fornecedores o atendimento a padrões relativos aos impactos ambientais, como consumo de energia, consumo de água, emissões no transporte e consumo de recursos naturais. Notadamente, esses critérios são os mais utilizados nas compras públicas, visto que os problemas ambientais já são discutidos há mais tempo e existem diversas leis, regulamentos e diretrizes relacionados ao tema em diversos países, como por 
exemplo, os padrões do manual Green Public Procurement (GPP), lançado pela União Europeia. Isso torna tais questões mais visíveis, sobrepondo-se àquelas associadas às outras dimensões da sustentabilidade.

Para que as aquisições sejam realmente sustentáveis, é necessário explorar a aplicabilidade de questões sociais às compras, de forma a estabelecer a ligação entre aspectos ambientais e sociais, debaixo do guarda-chuva das compras sustentáveis. Entretanto, essa tarefa nem sempre é fácil, dado o caráter essencialmente qualitativo que envolve algumas questões sociais.

No que se refere aos certificados ambientais (Ecolabel), os artigos apresentam a exigência de certificados como ISO 14000, EU Ecolabel e outros equivalentes, nas aquisições e contratações. Essa prática tem apresentado um crescimento expressivo nos últimos 20 anos, impulsionada pelo diferencial competitivo que gera para empresas fornecedoras de produtos e serviços e pelo aumento da consciência ambiental dos consumidores. Um exemplo disso é que, no período de 2016 a 2018, o número de produtos de rótulo ecológico da União Europeia (EU Ecolabel) disponíveis em toda a Europa apresentou um aumento de 86\% (European Commission, 2019). Nesse sentido, a rotulagem ambiental, quando exigida nas compras públicas, pode estimular os produtores em direção a inovações tecnológicas consideradas mais limpas.

Entretanto, embora os produtos com rótulo ecológico apresentem uma evolução significativa na participação do mercado global, a maior parte desse crescimento tem ocorrido em países desenvolvidos. Apesar dos esforços das ONGs em subsidiar os custos de certificação, incentivar os consumidores a adquirirem produtos certificados e pressionar os governos a estabelecer ambientes regulatórios favoráveis, a aceitação da rotulagem ambiental ainda ocorre de forma lenta nos países em desenvolvimento (Carlson e Palmer, 2016).

No Brasil, existem diversas certificações e selos verdes, referentes à agricultura orgânica, manejo florestal, conservação de energia, entre outros. No entanto, para suprir a falta de alternativas brasileiras para determinados tipos de certificação, muitas empresas têm procurado diretamente a certificação internacional, como é o caso da certificação Leed (Leadership in Energy and Environmental Design), para a construção civil. Contudo, o custo para as empresas obterem a certificação junto a credenciadores independentes ainda é alto, sobretudo para as pequenas e médias empresas, o que tem restringido seu uso.

Outra prática tratada repetidamente nos artigos é o atendimento a legislação específica, seja na aquisição de bens ou na contratação de serviços. As legislações podem ser locais, de uma região ou país, ou com maior abrangência, como é o caso das legislações da União Europeia. Essa prática demonstra que a intervenção regulatória do estado pode contribuir com a disseminação da informação relativa a produtos sustentáveis.

Um fator chave para as compras públicas sustentáveis é a forma como a legislação promulgada em nível nacional é interpretada dentro das estratégias políticas em nível local. Num país como o Brasil, onde as diferenças regionais são grandes, a forma como a legislação é implementada em cada região pode variar, já que determinados critérios podem não ser aplicáveis à realidade local exatamente como foram prescritos. Por outro lado, a ação voluntária e a colaboração no nível local entre os setores envolvidos podem resultar em práticas de aquisição sustentáveis que extrapolam os padrões mínimos regulamentados em nível nacional. Isso demonstra os efeitos de estruturas culturais e políticas em cada contexto regional, e que precisam ser levados em consideração no atendimento à legislação pertinente.

Algumas práticas apresentadas possuem grande importância, ainda que não sejam as mais recorrentes, por influenciarem em mais de uma dimensão da sustentabilidade. Por exemplo, a aquisição de produtos locais é uma prática que estimula a economia local (dimensão econômica), gera empregos (dimensões social e econômica) e reduz emissões no transporte (dimensão ambiental).

\subsection{Barreiras às compras públicas sustentáveis}

Dentre os artigos que relataram algum tipo de barreira/obstáculo para a implementação da compra pública sustentável, foram encontrados 13 diferentes tipos de barreiras, listadas na Tabela 5.

\section{Tabela 5 - Barreiras/obstáculos nas compras públicas sustentáveis}

\begin{tabular}{lc}
\hline \multicolumn{1}{c}{ Barreiras } & Quantidade de artigos \\
\hline [B01] Falta de informação sobre os produtos & 12 \\
[B02] Problemas de ordem financeira & 12 \\
$\begin{array}{l}\text { [B03] Falta de conhecimento por parte dos funcionários que trabalham com } \\
\text { compras públicas }\end{array}$ & 10
\end{tabular}

Revista de Gestão Social e Ambiental - RGSA, São Paulo, v. 13, n. 2, p. 21-39, maio/ago. 2019. 
[B04] Falta de apoio político ou organizacional 7

[B05] Ausência de fornecedor qualificado

[B06] Dificuldades para atendimento à legislação 5

[B07] Restrição à concorrência 4

[B08] Desinteresse / resistência à mudança 3

[B09] Desequilíbrio de partes da economia 2

[B10] Descrença nas políticas de governo ou falta destas 2

[B11] Dificuldade na obtenção de certificações e/ou ecolabels 2

[B12] Falta de incentivo ou pressão para adoção de compras públicas sustentáveis 1

[B13] Problemas relacionados a logística 1

Fonte: Elaborado pelos autores

As barreiras de falta de informação sobre os produtos [B01], problemas de ordem financeira [B02] e falta de conhecimento por parte dos funcionários que trabalham com compras públicas [B03] representaram $50 \%$ de todos os artigos encontrados nesta categoria (Figura 4).

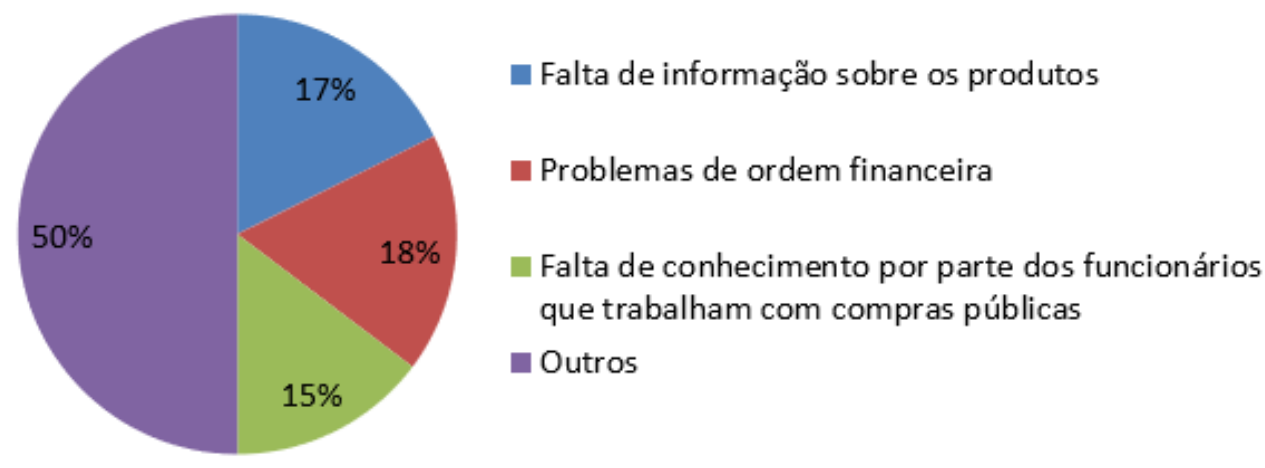

Figura 4 - Barreiras/obstáculos nas compras públicas sustentáveis

Fonte: Elaborado pelos autores

Ao citar a falta de informação sobre os produtos, os artigos analisados relatam que, na maioria dos casos, não existem informações suficientes disponíveis sobre os impactos ambientais ao longo do ciclo de vida dos bens ou serviços oferecidos. Desta forma, os compradores não possuem dados para avaliar efetivamente o grau de sustentabilidade de um produto, dificultando a comparação entre produtos ou sua correta especificação.

A rotulagem ambiental é uma ferramenta que pode ajudar nesta tarefa, pois traz indicações sobre o desempenho ambiental de produtos e serviços, permitindo a escolha daqueles que causam menor pressão sobre o meio ambiente e que estão de acordo com os critérios estabelecidos pelas licitações de compras públicas. No entanto, no Brasil, embora existam diversos sistemas de certificação e rotulagem, ainda há um número alto de selos autodeclarados, que carecem de maior transparência nas informações disponibilizadas, e, mesmo aqueles que têm certificação de uma terceira parte, necessitam de maior divulgação junto ao consumidor.

Outra ferramenta de apoio às compras sustentáveis são os catálogos de produtos sustentáveis, disponibilizados por alguns governos e entidades não-governamentais, normalmente por meio da internet, e que possuem informações a respeito das características socioambientais de determinados produtos. Entretanto, a presença de um produto no catálogo não tem o mesmo significado de uma certificação.

É importante também que o comprador estabeleça um diálogo com o mercado em todas as fases do processo de aquisição, por meio de análises de mercado e consultas, visto que o mercado conhece melhor as opções sustentáveis disponíveis. Além disso, não se deve limitar as compras sustentáveis à fase de especificação, pela inserção de critérios socioambientais nos documentos de licitação, mas incorporar a sustentabilidade em todas as fases do processo de aquisição. Especialmente na primeira fase, há muito espaço para alternativas sustentáveis. Por exemplo, diante da necessidade de um automóvel, pode-se questionar a necessidade de aquisição, contratar um serviço de leasing ou buscar uma alternativa mais limpa.

Revista de Gestão Social e Ambiental - RGSA, São Paulo, v. 13, n. 2, p. 21-39, maio/ago. 2019. 
No caso dos problemas de ordem financeira, a percepção é de que os custos dos produtos considerados sustentáveis são superiores aos dos produtos comuns, fazendo com que não haja interesse financeiro por parte das organizações para as compras sustentáveis. $\mathrm{Na}$ maioria das vezes, baseada no princípio da economicidade da legislação pertinente, a administração pública considera apenas o custo de aquisição do produto, desconsiderando os custos de utilização, tais como consumo de água e energia, custos de manutenção e descarte. Além disso, é preciso considerar os impactos socioambientais gerados pelo produto ao longo de todo o seu ciclo de vida, pois os produtos podem ter impactos totalmente diferentes durante as fases do seu ciclo de vida. Alguns materiais, como peças de alumínio, podem ter consequências ambientais adversas durante as fases de extração e processamento, mas serem pouco impactantes em uso e fáceis de reciclar. Por outro lado, uma impressora ou um produto alimentado por bateria vai gerar a maior parte do seu impacto ambiental durante a fase de utilização, devido aos materiais de consumo.

Aliado a isto, a redução das verbas disponíveis para o setor público e a imposição de restrições às suas despesas constituem um grande problema enfrentado pelas instituições públicas na tentativa de obter um resultado mais sustentável em suas aquisições. Tais problemas financeiros podem exercer pressão sobre os compradores públicos para que adotem a opção de menor custo, ao invés da que apresenta maior valor, e possam ser usados por alguns como desculpa para não abordar questões de sustentabilidade nas estratégias de aquisição. Esses problemas também podem representar uma restrição ao investimento em soluções mais sustentáveis, particularmente onde é necessário mais dispêndio inicial de capital para considerar a sustentabilidade.

A falta de conhecimento por parte dos funcionários que trabalham com compras públicas foi citada como um obstáculo porque muitos profissionais que trabalham na área de compras públicas não possuem conhecimento suficiente quanto a compras sustentáveis ou sobre o tema sustentabilidade. Isto pode ser atribuído à falta de formação sobre questões de sustentabilidade nas instituições de ensino e organismos profissionais, à falta de perspectiva a longo prazo, à confusão criada pelas várias interpretações de conceitos e indicadores, à falta de orientação clara e estruturada e à natureza dos códigos relevantes em termos de serem consultivos e não obrigatórios (Sourani e Sohail, 2011). Testa et al. (2016) ressaltam que a prática de aquisições públicas sustentáveis é determinada pelas ações e crenças dos indivíduos junto à estrutura organizacional, o que torna relevante que as pessoas envolvidas tenham conhecimento suficiente para se sentirem seguras e motivadas a aplicar esse conhecimento nas aquisições. Na ausência desse conhecimento, os profissionais responsáveis pelas compras públicas não exercitam e nem fomentam as aquisições sustentáveis em suas organizações.

\subsection{Benefícios das compras públicas sustentáveis}

A análise dos textos quanto aos benefícios e/ou vantagens das compras públicas sustentáveis mostrou 23 artigos com conteúdo relacionado, de onde foram extraídos os benefícios apresentados na Tabela 6 .

\section{Tabela 6 - Benefícios/vantagens das compras públicas sustentáveis}

\begin{tabular}{lc}
\multicolumn{1}{c}{ Benefícios } & $\begin{array}{c}\text { Quantidade de } \\
\text { artigos }\end{array}$ \\
\hline [V01] Redução da emissão de gases do efeito estufa e outros poluentes & 8 \\
[V02] Estímulo a atitudes sustentáveis no setor privado & 8 \\
[V03] Estímulo ao mercado de produtos sustentáveis & 7 \\
[V04] Estímulo à inovação & 6 \\
[V05] Estímulo ao desenvolvimento da economia local & 3 \\
[V06] Melhoria da eficiência e transparência & 3 \\
[V07] Melhoria da performance ambiental & 3 \\
[V08] Redução do consumo de água / consumo de água mais eficiente & 3 \\
[V09] Redução do consumo de energia / consumo de energia mais eficiente & 3 \\
[V10] Atendimento a grupos sociais em desvantagens (minorias) & 2 \\
[V11] Melhoria da performance econômica & 2 \\
[V12] Aumento de oportunidades de mercado e competitividade & 2 \\
[V13] Contribuição para metas de sustentabilidade mundial & 2
\end{tabular}

Revista de Gestão Social e Ambiental - RGSA, São Paulo, v. 13, n. 2, p. 21-39, maio/ago. 2019. 
[V14] Melhoria no ambiente e condições de trabalho 2

[V15] Redução de gastos / economia 2

[V16] Redução da geração de poluentes lançados na água 2

[V17] Aumento na geração de empregos 1

[V18] Estímulo à reciclagem 1

[V19] Melhoria da imagem da organização 1

[V20] Aumento da pressão da população 1

[V21] Estímulo a processos bem documentados, transparentes e participativos 1

[V22] Redução da geração de poluentes lançados no solo 1

[V23] Redução do uso de embalagens 1

[V24] Redução da pegada de carbono 1

Fonte: Elaborado pelos autores

Os quatro principais benefícios encontrados nos artigos analisados totalizaram $44 \%$ desta categoria (Figura 5).
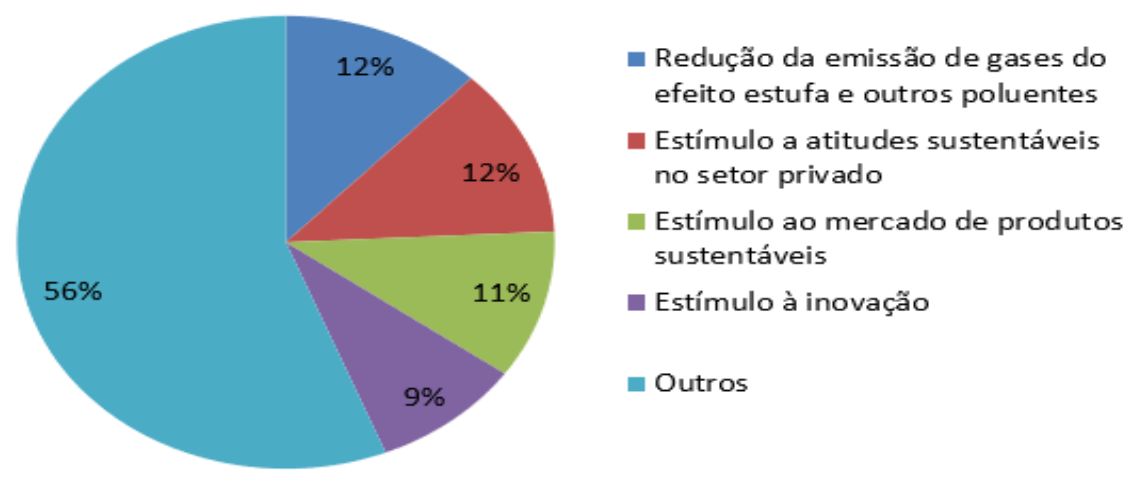

Outros

Figura 5 - Principais benefícios das compras públicas sustentáveis

Fonte: Elaborado pelos autores

A aplicação de critérios de sustentabilidade nas compras públicas implica em benefícios não apenas para a organização pública, mas também para toda a cadeia produtiva e para a sociedade em geral. Os benefícios apresentados conservam uma relação direta com as práticas sustentáveis listadas na Tabela 4. Dessa forma, a redução da emissão de gases do efeito estufa e outros poluentes (V01) pode ser alcançada por algumas práticas, tais como P05, P06 e P07. A compra de produtos locais, por exemplo, utiliza cadeias de suprimento mais curtas, que colaboram com a redução das emissões de gases do efeito estufa e a poluição das cidades. Além disso, existem outras motivações para aplicar esta prática, como a melhoria da economia local, a defesa de produtos locais tradicionais ou o incentivo ao consumo de alimentos saudáveis de produtores locais. Da mesma forma, uma política de compras que privilegie uma opção logística menos intensiva em combustível fóssil, também estará contribuindo com a redução das emissões de gases do efeito estufa, ao mesmo tempo em que incentiva o desenvolvimento de tecnologias mais limpas.

Outro benefício muito citado é que as compras públicas sustentáveis estimulam atitudes sustentáveis no setor privado (V02), que pode ser atribuído à adoção de algumas práticas, tais como P02, P09, P12 e P13, uma vez que essas atitudes sustentáveis passam a ser exigências para que uma empresa seja considerada um fornecedor nas compras efetuadas pelo poder público. Neste caso, o poder de compra do setor público pode ser usado para influenciar as empresas a investir em tecnologias mais verdes e contribuir para metas de sustentabilidade locais, regionais, nacionais e internacionais. Porém, como afirma Lundberg et al. (2016), do ponto de vista da política ambiental, é crucial que a especificação de critérios ambientais ocorra com referência a objetivos ambientais definidos e que vá além do padrão ambiental da tecnologia das empresas poluidoras, a fim de fomentar a inovação. Os fornecedores envolvidos no processo de aquisição devem fazer parte do problema ambiental, de modo a acreditar que vale a pena apresentar uma proposta e decidir ajustar o seu produto de acordo com os critérios especificados. Além disso, também é importante investigar o tradeoff entre os benefícios ambientais obtidos pela prática de compras públicas sustentáveis e a perda em termos de aumento de custos devido a um menor número de propostas qualificadas (Cheng et al., 2018).

Revista de Gestão Social e Ambiental - RGSA, São Paulo, v. 13, n. 2, p. 21-39, maio/ago. 2019. 
A evidência do benefício V03 (estímulo ao mercado de produtos sustentáveis) desempenha papel relevante, uma vez que, segundo Chiarini e Vagnoni (2015), sem o estímulo promovido pelas compras públicas, muitos produtos e serviços sustentáveis teriam dificuldades para entrar no mercado.

Alguns produtos sustentáveis tendem a ter um custo inicial mais elevado, porque incluem compensações no preço pelas novas tecnologias e materiais empregados ou pelo design diferenciado. Isto constitui uma barreira para a entrada desses produtos no mercado e, se não houver incentivo para estes tipos de produto, sua permanência no mercado poderá estar comprometida. À medida que ocorre um crescimento da demanda, estes produtos são produzidos em maior quantidade e o custo tende a cair. Depreende-se daí a importância do estímulo induzido pelas compras públicas sustentáveis a esse segmento de mercado. Entretanto, não se trata de priorizar produtos sustentáveis, mas considerar na avaliação não apenas o aspecto financeiro, como também os benefícios socioambientais do produto.

\subsection{Aspectos contraditórios das compras públicas sustentáveis}

Os artigos analisados apresentam abordagens e interpretações diferentes para um mesmo assunto, como é o caso de legislações sobre compras públicas sustentáveis. Enquanto 13 artigos relatam que as legislações são práticas que fomentam a implementação das compras sustentáveis, outros cinco artigos identificam o atendimento a estas legislações como um fator que dificulta sua implantação. Por exemplo, Attwater (2014) ressalta que nas compras federais canadenses as incertezas legais ao incluir considerações de desempenho ambiental são um impedimento para a implementação de compras públicas sustentáveis.

Vários estudos analisados, tais como os de Witjes e Lozano (2016) e Cheng et al. (2018), consideram que o setor público, através de seu poder de compra, tem grande capacidade de influenciar o mercado, promovendo a demanda e ampliando o mercado de produtos e serviços sustentáveis. Por outro lado, autores como Lundberg et al., (2016) e Marron (1997) não acreditam que o poder de mercado do setor público seja uma condição suficiente para que as compras públicas sustentáveis funcionem adequadamente, podendo causar resultados contraproducentes.

Além disso, enquanto Castro, Freitas e Cruz (2014) afirmam que as compras públicas sustentáveis causam restrição à concorrência, uma vez que são limitadas às empresas que atendem aos critérios estabelecidos, Majerník et al. (2017) identificam as compras públicas sustentáveis como promotoras da competitividade.

A exigência de certificados ambientais e/ou ecolabels aparece nesse estudo como a segunda prática mais usual nas compras públicas sustentáveis, embora Cerutti et al. (2018) e Attwater (2014) afirmem que a obtenção desses certificados constitui uma barreira para as empresas participarem das compras públicas, especialmente as pequenas empresas.

Adicionalmente, observou-se que a maioria das práticas adotadas nas compras públicas sustentáveis e relatadas nos estudos analisados atende direta ou indiretamente à dimensão ambiental do tripé da sustentabilidade. Poucas são as práticas adotadas que incluem as demais dimensões. Como consequência, a maior parte dos benefícios encontrados também se enquadram na dimensão ambiental.

\section{CONSIDERAÇÕES FINAIS}

O objetivo deste estudo foi mapear as principais práticas adotadas nas compras públicas sustentáveis e os principais benefícios e obstáculos destas aquisições. Este mapeamento configura-se como uma pesquisa pioneira nesta área. A categorização das publicações disponíveis na literatura científica contribui para que os pesquisadores tenham uma síntese do que é atualmente abordado nesse tema. Além disso, as organizações públicas que almejam adotar as compras públicas sustentáveis podem usar o estudo como ponto de partida para identificar exemplos de práticas para definir o rumo de suas contratações, explorar as vantagens dessas práticas e buscar mitigar as possíveis dificuldades que podem ser encontradas em suas contratações.

Com base nos resultados encontrados, observa-se que a maior parte dos artigos se concentra nas práticas sustentáveis que são realizadas nas contratações públicas, o que inclui em especial, a adoção de critérios de performance ambiental, certificados e selos ambientais (ecolabels) e legislações para normalização dessas compras/licitações.

Os estudos analisados indicam que a prática de compras públicas sustentáveis precisa superar desafios significativos, incluindo a falta de informação sobre os produtos, problemas de ordem financeira e a falta de conhecimento e conscientização ambiental. A ocorrência dessas barreiras sinaliza para a necessidade 
de se investir em rotulagem ambiental, políticas públicas para aquisições sustentáveis e capacitação das equipes que trabalham com compras públicas.

Pode-se inferir ainda que, apesar da preocupação com a sustentabilidade nos processos de compras ser um tema relativamente novo, verifica-se o seu crescimento e sua exigência nos meios produtivos e de prestação de serviços, tanto nas organizações privadas como públicas. Esse crescimento se deve principalmente à pressão de organismos internacionais, exigência dos consumidores ou pela preocupação e necessidade em adotar meios sustentáveis na produção de bens e serviços. Por outro lado, a existência de abordagens e interpretações distintas em relação aos conceitos que envolvem a aplicação de critérios de sustentabilidade no processo de compras públicas pode dificultar sua implementação.

Contudo, à medida que os governos assumem mais autoridade e responsabilidade pelo incentivo a práticas sustentáveis, a transição para aquisições mais sustentáveis passa a depender da vontade política e da liderança assumida pelos gestores públicos, além da existência de uma infraestrutura capaz de equilibrar a complexa relação entre fatores econômicos, ambientais e sociais.

Este estudo evidenciou as práticas, bem como os obstáculos e benefícios nas compras públicas sustentáveis, porém é importante destacar também o estágio atual desses aspectos nas organizações privadas. Para trabalhos futuros, sugere-se a realização de uma revisão sistemática, nos mesmos moldes desta, abrangendo as organizações privadas, a fim de possibilitar uma análise comparativa com os resultados obtidos neste trabalho.

\section{REFERÊNCIAS}

Adjei, A. B. (2010). Sustainable public procurement: a new approach to good governance. Seul: IPPC4, 2010. Recuperado em: 25 jul.2018, de: <www.ippa.org/IPPC4/Proceedings/07GreenProcurement/ Paper710.pdf $>$.

Ahsan, K., Rahman, S. (2017). Green public procurement implementation challenges in Australian public healthcare sector. Journal of Cleaner Production, 152, 181-197.

Alencastro, M. A. C., Silva, E. V., Lopes, A. M. D. (2014). Contratações sustentáveis na administração pública brasileira: a experiência do Poder Executivo Federal. Revista de Administração Pública, 48, 207-35.

Ambe, I. M., Badenhorst-Weiss, J. A. (2012). Procurement challenges in the South African public sector. Journal of transport and supply chain management, 6, 242-261.

Appolloni, A., Sun, H., Jia, F., Li, X. (2014). Green Procurement in the private sector: a state of the art review between 1996 and 2013. Journal of Cleaner Production, 85, 122-133.

Attwater, D. M. (2014). Promoting sustainable development with canadian public procurement. Public Contract Law Journal, 44, 79-110.

Biderman, R., Macedo, L. S. V., Monzoni, M., Mazon, R. (2008). Guia de compras públicas sustentáveis: uso do poder de compra do governo para a promoção do desenvolvimento sustentável. (2. ed.) Rio de Janeiro: Editora FGV.

Brammer, S., Walker, H. (2011). Sustainable procurement in the public sector: an international comparative study. International Journal of Operations \& Production Management, 31(4), 452-476.

Carlson, A., Palmer, C. (2016). A qualitative meta-synthesis of the benefits of eco-labeling in developing countries. Ecological Economics, 127, 129-145.

Castro, J. K., Freitas, C. L., Cruz, F. (2014). Licitações sustentáveis: um estudo em instituições federais de ensino superior na região sul do Brasil. Revista Metropolitana de Sustentabilidade - RMS, 4, 31-51.

Cerutti, A. K. et al. (2018). Modelling, assessing, and ranking public procurement options for a climatefriendly catering service. The International Journal of Life Cycle Assessment, 23, 95-115.

Cheng, W. et al. (2018). Green public procurement, missing concepts and future trends e acritical review. Journal of Cleaner Production, 176, 770-784.

Chiarini, A., Vagnoni, E. (2015). Environmental sustainability in European public healthcare: Could it just be a matter of leadership? Leadership in Health Services, 29, 2-8.

Revista de Gestão Social e Ambiental - RGSA, São Paulo, v. 13, n. 2, p. 21-39, maio/ago. 2019. 
Chiarini, A., Opoku, A., Vagnoni, E. (2017). Public healthcare practices and criteria for a sustainable procurement: a comparative study between UK and Italy. Journal of Cleaner Production, 162, 391-399.

Cmmad (1987). Report of the World Commission on Environment and Development: Our Common Future. Transmitted to the General Assembly as an Annex to document A/42/427 - Development and International Cooperation: Environment. United Nations, 1987.

Defra - Department for Environment, Food and Rural Affairs, 2006. Procuring the Future - Sustainable Procurement National Action Plan: Recommendations from the Sustainable Procurement Task Force. London: Crown. De: em: $<$ https://

www.gov.uk/government/uploads/system/uploads/attachment_data/file/69417/pb11710-procuring-thefuture-060607.pdf>. Acesso em: 10 març.2019.

European Commission (2019). Ecolabel: facts and figures. Recebido em 10 mar.2019, de:

$<\mathrm{http}$ ://ec.europa.eu/environment/ecolabel/facts-and-figures.html $>$.

Grandia, J., Steijn, B., Kuipers, B. (2015). It is not easy being green: increasing sustainable public procurement behaviour, Innovation: The European Journal of Social Science Research, 28(3), 243-260.

Iclei.(2015) Manual Procura+ Um guia para implementação de compras públicas sustentáveis, (3. ed.) São Paulo: Iclei Brasil.

Kitchenham, B. (2007). Guidelines for performing systematic literature reviews in software engineering. Ebse Technical Report. Keele University and Durham University, UK.

Kunzlik, P. (2013). Green public procurement european law, environmental standards and 'what to buy' decisions. Journal of Environmental Law, 25(2), 173-202.

Lehtinen, U. (2012). Sustainability and local food procurement: a case study of Finnish public catering. British Food Journal, 114(8), 1053-1071.

Lundberg, S., Marklund, P., Strömbäck, E. (2016). Is environmental policy by public procurement effective? Journal Public Finance Review, 44(4), 478-499.

Marron, D. B. (1997). Buying green: government procurement as an instrument of environmental policy. Public Finance Review, 25(3), 285-305.

Majerník, M., Daneshjo, N., Chovancová, J., Sančiová, G. (2017). Modelling the process of green public procurement. TEM Journal, 6(2), 272-278.

McMurray, A. J. et al. (2014). Sustainable procurement in Malaysian organizations: practices, barriers and opportunities. Journal of Purchasing and Supply Management, 20(3), 195-207.

Mitra, S., Webster, S. (2008). Competition in remanufacturing and the effects of government subsidies. International Journal of Production Economics, 111(2), 287-298.

Neto, B., Caldas, M. G. (2018). The use of green criteria in the public procurement of food products and catering services: a review of EU schemes. Environment, Development and Sustainability. 20(5), 1905-1933.

Pacheco-Blanco, B., Bastante-Ceca, M. J. (2016). Green public procurement as an initiative for sustainable consumption. An exploratory study of Spanish public universities. Journal of Cleaner Production, 133, 648656.

Palacios, M., Ángel, S. (2014). Hacia la implementación de patrones de sostenibilidad ambiental en la producción y consumo: compras públicas sostenibles. Revista Derecho \& Sociedad, 42, 201-212.

Powell, J. C., Tinch, T., White, O., Peters, M. (2006). Successful approaches to sustainable procurement: a report to the department for environment. Food and Rural Affaires. Environmental Futures Ltd. Defra, London, United Kingdom.

Preuss, L. (2001). In dirty chains? Purchasing and greener manufacturing. Journal of Business Ethics, 34(3), 345-359.

Preuss, L. (2011). On the contribution of public procurement to entrepreneurship and small business policy. Entrepreneurship \& Regional Development, 23(9-10), 787-814. 
Rebane, K., Reihan, A. (2016). Promoting building materials that have lower embodied carbon and energy in public procurements: experience from Estonia. Management of Environmental Quality: An International Journal, 27(6), 722-739.

Sourani, A., Sohail, M. (2011). Barriers to addressing sustainable construction in public procurement strategies. Proceedings of the Institution of Civil Engineers: Engineering Sustainability, 164 (4), 229-237.

Sustainable Procurement Task Force. (2006). Procuring the Future: Sustainable Procurement National Action Plan, London: Department for Environment, Food and Rural Affairs (Defra).

Testa, F. et al. (2016). Drawbacks and opportunities of green public procurement: an effective tool for sustainable production. Journal of Cleaner Production, 112(3), 1893-1900.

Urban, K. M. (2015). Sustainable acquisition and the post-conflict environment: why adopting a federal sustainable procurement policy for post-conflict environments that mirrors those adopted by some local governments would help lead to mission success. Public Contract Law Journal, 44(2), 261-284.

Uttam, K., Roos, C. L. L. (2015). Competitive dialogue procedure for sustainable public procurement. Journal of Cleaner Production, 86, 403-416.

Walker, H., Brammer, S. (2012). The relationship between sustainable procurement and e-procurement in the public sector. International Journal of Production Economics, 140(1), 256-268.

Walker, H., Miemczyk, J., Johnsen, T., Spencer, R. (2012). Sustainable procurement: past, present and future. Journal of Purchasing \& Supply Management, 18, 201-206.

Witjes, S., Lozano, R. (2016). Towards a more circular economy: proposing a framework linking sustainable public procurement and sustainable business models. Resources, Conservation and Recycling, 112, 37-44.

\section{APÊNDICE A - LISTA COMPLETA DE TODOS OS ARTIGOS INCLUÍDOS NA REVISÃO SISTEMÁTICA DE LITERATURA}

[A1] Rietbergen, M. G., Blok, K. (2013). Assessing the potential impact of the $\mathrm{CO}_{2}$ Performance Ladder on the reduction of carbon dioxide emissions in the Netherlands. Journal of Cleaner Production, 52, 33-45.

[A2] Bratt, C. et al. (2013). Assessment of criteria development for public procurement from a strategic sustainability perspective. Journal of Cleaner Production, 52, 309-316.

[A3] Fernández-Viñé, M. B. et al. (2013). Assessment of the public administration tools for the improvement of the eco-efficiency of Small and Medium Sized Enterprises. Journal of Cleaner Production, 47, 265-273.

[A4] Smith, J. et al. (2016). Balancing competing policy demands: the case of sustainable public sector food procurement. Journal of Cleaner Production, 112, 249-256.

[A5] Cerutti, A. K. et al. (2016). Carbon footprint in green public procurement: policy evaluation from a case study in the food sector. Food Policy, 58, 82-93.

[A6] Uttam, K., Le, C., Roos, L. (2015). Competitive dialogue procedure for sustainable public procurement. Journal of Cleaner Production, 86, 403-416.

[A7] Alencastro, M. A. C., Silva, E. V., Lopes, A. M. D. (2014). Contratações sustentáveis na administração pública brasileira: a experiência do Poder Executivo federal. Revista de Administração Pública, 48, 207-35.

[A8] Testa, F. et al. (2016). Drawbacks and opportunities of green public procurement: an effective tool for sustainable production. Journal of Cleaner Production, 112(3), 1893-1900.

[A9] Amann, M. et al. (2014). Driving sustainable supply chain management in the public sector: The importance of public procurement in the European Union. Supply Chain Management: An International Journal, 19(3), 351-366.

[A10] García-Erviti, F., Armengot-Paradinas, J., Ramírez-Pacheco, G. (2015). El análisis del coste del ciclo de vida como herramienta para la evaluación económica de la edificación sostenible. Estado de la cuestión. Informes de la construccion, $67,537$.

[A11] Chiarini, A., Vagnoni, E. (2015). Environmental sustainability in European public healthcare: Could it just be a matter of leadership? Leadership in Health Services, 29, 2-8.

[A12] Testa, F. et al. (2014). Examining green public procurement using content analysis: existing difficulties for procurers and useful recommendations. Environment, Development and Sustainability, 18, 197-219.

[A13] Fisher, E., Corbalán, S. (2013). Fair trade and European public procurement: legal principles and governance dynamics. Social Enterprise Journal, 9, 11-27.

[A14] Souza, P., Pfitscher, E. (2013). Gestão e sustentabilidade ambiental: Estudo em um órgão público do Estado de Santa Catarina. Revista de Contabilidade e Controladoria, 5(3), 8-32.

[A15] Tolan Jr, P. E. (2012). Going-going-green: strategies for fostering sustainable new federal buildings. Public Contract Law Journal, 41(2), 233-295.

[A16] Simcoe, T., Toffe, M. W. (2014). Government green procurement spillovers: Evidence from municipal building policies in California. Journal of Environmental Economics and Management, 68(3), 411-434.

[A17] Agyepong, A. O., Nhamo, G. (2017). Green procurement in South Africa: perspectives on legislative provisions in metropolitan municipalities. Environment, Development and Sustainability, 19(6), 2457-2474. 
[A18] Clement, S. (2014). Green procurement: Clean Fleets project. LAPV, 28-29.

[A19] Pacheco-Blanco, B., Bastante-Ceca, M. J. (2016). Green public procurement as an initiative for sustainable consumption. An exploratory study of Spanish public universities. Journal of Cleaner Production, 133, 648-656.

[A20] Kunzlik, P. (2013). Green Public Procurement European Law, Environmental Standards and 'What To Buy’ Decisions. Journal of Environmental Law, 25(2), 173-202.

[A21] Ahsan, K., Rahman, S. (2017). Green public procurement implementation challenges in Australian public healthcare sector. Journal of Cleaner Production, 152, 181-197.

[A22] Brusselaers, J., Huylenbroeck, G. V., Buysse, J. (2017). Green Public Procurement of Certified Wood: Spatial Leverage Effect and Welfare Implications. Ecological Economics, 135(3), 91-102.

[A23] Cheng, W. et al. (2018). Green Public Procurement, missing concepts and future trends e Acritical review. Journal of Cleaner Production, 176, 770-784.

[A24] Aragão, C. G., Jabbour, C. J. C. (2017). Green training for sustainable procurement: Insights from the Brazilian public sector. Industrial and Commercial Training, 49, 48-54.

[A25] Hall, P., Löfgren, K., Peters, G. (2016). Greening the Street-Level Procurer: Challenges in the Strongly Decentralized Swedish System. Journal of Consumer Policy, 39(4), 467-483.

[A26] Palacios, M., Ángel, S. (2014). Hacia la Implementación de Patrones de Sostenibilidad Ambiental en la Producción y Consumo: Compras Públicas Sostenibles. Revista Derecho \& Sociedad, 42, 201-212.

[A27] Igarashi, Mieko. Boer, Luitzende.. Michelsen, Ottar. (2015). Investigating the anatomy of supplier selection in green public procurement. Journal of Cleaner Production, 108, 442-450.

[A28] Lundberg, S., Marklund, P., Strömbäck, E. (2016). Is Environmental Policy by Public Procurement Effective? Journal Public Finance Review, 44(4), 478-499.

[A29] Grandia, J., Steijn, B., Kuipers, B. (2015). It is not easy being green: increasing sustainable public procurement behaviour, Innovation: The European Journal of Social Science Research, 28(3), 243-260.

[A30] Castro, J. K. et al. (2013). Licitações públicas sustentáveis: um estudo em um ministério do Brasil. Revista Ambiente Contábil, 5(2), 86-106.

[A31] Castro, J. K., Freitas, C. L., Cruz, F. (2014). Licitações sustentáveis: um estudo em instituições federais de ensino superior na região sul do Brasil. Revista Metropolitana de Sustentabilidade - RMS, 4(1), 31-51.

[A32] Majerník, M. et al. (2017). Modelling the process of green public procurement. TEM Journal, 6(2), 272-278.

[A33] Cerutti, A. K. et al. (2018). Modelling, assessing, and ranking public procurement options for a climate-friendly catering service. The International Journal of Life Cycle Assessment, 23, 95-115.

[A34] Zhu, Q., Geng, Y., Sarkis, J. (2013). Motivating green public procurement in China: an individual level perspective. Journal of Environmental Management, 126, 85-95.

[A35] Araújo, G. C., Teixeira, C. E. (2016). Operationalization of sustainable procurement in the department of penitentiary administration of the state of São Paulo. Revista Metropolitana de Sustentabilidade - RMS, 6(3), 63-86.

[A36] Nijaki, L. K., Worrel, G. (2012). Procurement for sustainable local economic development. International Journal of Public Sector Management, 25(2), 133-153.

[A37] Rebane, K., Reihan, A. (2016). Promoting building materials that have lower embodied carbon and energy in public procurements: experience from Estonia. Management of Environmental Quality: An International Journal, 27(6),722-739.

[A38] Attwater, D. M. (2014). Promoting sustainable development with canadian public procurement. Public Contract Law Journal, 44(1), 79-110.

[A39] Chiarini, A., Opoku, A., Vagnoni, E. (2017). Public healthcare practices and criteria for a sustainable procurement: A comparative study between UK and Italy. Journal of Cleaner Production, 162, 391-399.

[A40] D'Hollander, D., Marx, A. (2014). Strengthening private certification systems through public regulation: The case of sustainable public procurement. Sustainability Accounting, Management and Policy Journal, 5(1), 2-21.

[A41] Lehtinen, U. (2012). Sustainability and local food procurement: a case study of Finnish public catering. British Food Journal, 114(8), 1053-1071.

[A42] Urban, K. M. (2015). Sustainable acquisition and the post-conflict environment: why adopting a federal sustainable procurement policy for post-conflict environments that mirrors those adopted by some local governments would help lead to mission success. Public Contract Law Journal, 44(2), 261-284.

[A43] Luttenberger, A., Luttenberger, L. R. (2017). Sustainable procurement and environmental life - cycle costing in maritime transport. WMU Journal of Maritime Affairs, 16(2), 219-231.

[A44] McMurray, A. J. et al. (2014). Sustainable procurement in Malaysian organizations: practices, barriers and opportunities. Journal of Purchasing and Supply Management, 20(3), 195-207.

[A45] Filippini, R. et al. (2018). Sustainable school food procurement: what factors do affect the introduction and the increase of organic food? Food Policy, 76, 109-119.

[A46] Oruezabala, G., Rico, J. (2012). The impact of sustainable public procurement on supplier management - The case of French public hospitals. Industrial Marketing Management, 41(4), 573-580.

[A47] Walker, H., Brammer, S. (2012). The relationship between sustainable procurement and e-procurement in the public sector. International Journal of Production Economics, 140(1), 256-268.

[A48] Witjes, S., Lozano, R. (2016). Towards a more circular economy: proposing a framework linking sustainable public procurement and sustainable business models. Resources, Conservation and Recycling, 112, 37-44.

[A49] Mogre, R., Lindgreen, A., Hingley, M. (2017). Tracing the evolution of purchasing research: future trends and directions for purchasing practices. Journal of Business \& Industrial Marketing, 32(2), 251-257.

[A50] Delmonico, D. et al. (2018). Unveiling barriers to sustainable public procurement in emerging economies: evidence from a leading sustainable supply chain initiative in Latin America. Resources, Conservation and Recycling, 134, 70-79.

[A51] Lundberg, S. et al. (2015). Using public procurement to implement environmental policy: an empirical analysis. Environmental Economics and Policy Studies, 17(4), 487-520. 
[A52] Testa, F., Iraldo, F., Frey, M., Daddi, T. (2012). What factors influence the uptake of GPP (green public procurement) practices? New evidence from an Italian survey. Ecological Economics, 82, 88-96. 